\title{
A Survey of Vitamin D Status in Patients with Degenerative Diseases of the Spine
}

\author{
Farid Zolfaghari ${ }^{1}$, Alireza Faridmoayer ${ }^{1}$, Bahram Soleymani ${ }^{2}$, \\ Mohammadreza Taji ${ }^{3}$, Maryam Mahabadi ${ }^{4}$ \\ ${ }^{1}$ Department of Neurosurgery, School of Medicine, Najafabad Branch, Islamic Azad University, Isfahan, Iran \\ ${ }^{2}$ Department of Health, School of Medicine, Najafabad Branch, Islamic Azad University, Isfahan, Iran \\ ${ }^{3}$ Young Researchers and Elite Club, Najafabad Branch, Islamic Azad University, Isfahan, Iran \\ ${ }^{4}$ School of Medicine, Najafabad Branch, Islamic Azad University, Isfahan, Iran
}

\begin{abstract}
Study Design: Descriptive cross-sectional study.
Purpose: To determine the prevalence of vitamin D deficiency in patients with degenerative diseases of the spine about to undergo spinal surgery and the relations between such deficiency and potential risk factors.

Overview of Literature: Vitamin D has a major role in musculoskeletal system health maintenance. Recently, studies on degenerative diseases of the spine have shown a high prevalence of vitamin $D$ deficiency in patients undergoing spine surgery.

Methods: Serum levels of 25(OH)D were determined by an electrochemiluminescence detection assay. The other variables were determined through relevant questionnaires, and the data was analyzed through analysis of variance, $t$-test, chi-square and multivariate logistic regression analysis.

Results: A total of 110 patients were enrolled in the study. The mean serum level of $25(\mathrm{OH}) \mathrm{D}$ was $27.45 \pm 18.75 \mathrm{ng} / \mathrm{mL}$, and $44.5 \%$ of patients showed vitamin $\mathrm{D}$ deficiency $(25(\mathrm{OH}) \mathrm{D}<20 \mathrm{ng} / \mathrm{mL})$, with an additional $17.3 \%$ of patients having a serum level of $25(\mathrm{OH}) \mathrm{D}$ that was insufficient $(20 \leq 25(0 H) D<30 \mathrm{ng} / \mathrm{mL})$. The prevalence of vitamin $D$ deficiency was significantly higher in the younger age group compared to the older age group $(p<0.001)$ and the ones without a history of taking vitamin $D$ supplements $(p=0.013)$. Compared to men, women showed significantly higher levels of vitamin $D(p=0.029)$.

Conclusions: A high prevalence of vitamin D deficiency is seen in patients with degenerative diseases of the spine. On the other hand, the conventional risk factors such as old age or female sex alone did not seem to be sufficient in determining the likelihood of deficiency. Thus, it is recommended that vitamin $\mathrm{D}$ deficiency prevention strategies comprise a broader spectrum of the population through which such degenerative diseases and their consequences may be prevented or delayed.
\end{abstract}

Keywords: Spine; Intervertebral disc degeneration; Vitamin D; 25-Hydroxyvitamin D; Neurosurgery

\section{Introduction}

Vitamin $\mathrm{D}$ is a fat-soluble steroid with the vast majority $(80 \%-90 \%)$ of the vitamin D required by the body is pro- vided by the conversion of precursors in the skin under the influence of UV light, usually from the sun; the rest $(10 \%-20 \%)$ comes through food intake. It has been shown that vitamin $\mathrm{D}$ is involved in proliferation, differentiation,

\footnotetext{
Received Jan 17, 2016; Revised Mar 18, 2016; Accepted Apr 8, 2016

Corresponding author: Mohammadreza Taji

Najafabad Branch, Islamic Azad University, Islamic Azad University of Najafabad, University Sq.,

Najafabad, Isfahan, Iran P.O.Box:85141-43131

Tel: +98-91-3319-5760, Fax: +98-31-4229-1016, E-mail: taji.mr20@gmail.com
} 
and maturation of chondrocytes [1], synthesis of proteoglycans-making up the matrix of intervertebral discsand also in regulation of plasma sulfate levels required for intracellular sulfation of proteoglycans [2]. For the health of intervertebral discs, active metabolites of vitamin $\mathrm{D}$ regulate proliferation, expression of matrix genes and production of certain proteins and cytokines in cells of annulus fibrosus and nucleus pulposus, the two macrostructural components of the discs [3,4].

Spine diseases are relatively common among the musculoskeletal diseases so that $50 \%-80 \%$ of adults experience at least one episode of low back pain (LBP) in their lifetime [5], and intervertebral disc degeneration is one of the primary causes considered for LBP [6].

Several studies have shown the epidemic hypovitaminosis D in today's society-both in developed and developing countries-and various studies have been conducted on the effects of vitamin D deficiency and its risk factors in various diseases including musculoskeletal diseases. However, according to our literature search, few studies have been devoted to degenerative diseases of the spine. Yet, some recent reports in this area have indicated a high prevalence of vitamin $\mathrm{D}$ deficiency in these patients [7-10].

Considering the issues resulting from vitamin $\mathrm{D}$ deficiency in the musculoskeletal system as well as the medical need to address degenerative spinal lesions and the individual and societal costs involved-such as with reconstructive surgery-it seemed rational to conduct a study on evaluating the vitamin D levels in patients with degenerative disease of the spine.

\section{Materials and Methods}

The research was an observational descriptive study in a cross-sectional format. It used convenience sampling to select the subjects. All the eligible patients had been referred to the neurosurgery unit in the Shariati Hospital in Isfahan, Iran, and were enrolled until a predetermined number of patients were reached. The sampling procedure began in late fall of 2013 and continued until late summer of 2014 .

\section{Inclusion criteria}

Adult patients with degenerative spinal diseases such as intervertebral disc herniation, spinal canal stenosis (based on magnetic resonance imaging, MRI) and spinal instability (defined as "functional instability," which refers to a lack of neuromuscular control of the joint during activities) who had not responded to conservative and medical treatments, and thus were scheduled for a surgical procedure, were recruited after indicating their consent.

\section{Exclusion criteria}

These included: (1) history of any fracture in the last month, (2) any infection or malignancy in the spine, (3) inflammatory spondyloarthropathy, (4) evidence of metabolic bone disease (such as hypo- and hyperparathyroidism), (5) concomitant diseases influencing vitamin D metabolism (including chronic liver and kidney disease, malabsorption, systemic infections and neoplasms), (6) psychiatric disorders and neurodegenerative disorders, and (7) patient withdrawal of participation in the project.

\section{Data collection tools}

For the study, blood samples were collected over a oneweek period before the surgery and then analyzed by an autoanalyzer device (Roche/Hitachi Diagnostic Elecsys 2010 Immunoassay), and the $25(\mathrm{OH}) \mathrm{D}$ serum levels were determined. The test was via competitive protein binding with electrochemiluminescence detection.

According to previous studies [11-13], patients were divided into 3 groups based on the serum level of 25(OH)D: (1) Deficient group: defined by the serum level of $25(\mathrm{OH})$ $\mathrm{D}<20 \mathrm{ng} / \mathrm{mL}$. (2) Insufficient group: defined by the serum level of $20 \leq 25(\mathrm{OH}) \mathrm{D}<30 \mathrm{ng} / \mathrm{mL}$. (3) Normal group: defined by the serum level of $25(\mathrm{OH}) \mathrm{D} \geq 30 \mathrm{ng} / \mathrm{mL}$.

Patient body mass index (BMI) values were calculated from their height and weight, and they were classified into 4 BMI groups, based on the CDC classification [14]: (1) Underweight $\left(\mathrm{BMI}<18.5 \mathrm{~kg} / \mathrm{m}^{2}\right)$, (2) Normal weight $\left(18.5 \leq \mathrm{BMI}<25 \mathrm{~kg} / \mathrm{m}^{2}\right)$, (3) Overweight $(25 \leq \mathrm{BMI}<30 \mathrm{~kg} /$ $\left.\mathrm{m}^{2}\right)$, (4) Obese $\left(30 \leq \mathrm{BMI} \mathrm{kg} / \mathrm{m}^{2}\right)$.

Interviews and questionnaires were used to determine the status of other variables including age, sex, smoking status, whether taking vitamin $\mathrm{D}$ supplements and pain severity. Age values were categorized into three groups: (1) 20 to 39 years old (young), (2) 40 to 59 years (middleaged), and (3) $\geq 60$ years (old). 
Table 1. Supplement consumption status in different groups of age, sex, smoking

\begin{tabular}{|c|c|c|c|}
\hline \multirow{2}{*}{ Variable } & \multicolumn{2}{|c|}{ Vitamin D supplement } & \multirow{2}{*}{$p$-value } \\
\hline & No & Yes & \\
\hline Age group & & & 0.58 \\
\hline Young & $18(66.7)$ & $9(33.3)$ & \\
\hline Middle age & $42(61.8)$ & $26(38.2)$ & \\
\hline Elderly & $7(50.0)$ & $7(50.0)$ & \\
\hline Sex & & & $<0.001$ \\
\hline Male & 43 (79.6) & $11(20.4)$ & \\
\hline Female & $24(43.6)$ & $31(56.4)$ & \\
\hline \multicolumn{4}{|l|}{ Smoking } \\
\hline Yes & $13(86.7)$ & $2(13.3)$ & 0.032 \\
\hline No & $53(57.6)$ & $39(42.4)$ & \\
\hline Total population & 67 (61.5) & 42 (38.5) & - \\
\hline
\end{tabular}

Smoking was defined as habitual cigarette smoking during the last 6 months. The history of taking the vitamin D supplements was defined as the consumption of any pharmaceutical products containing vitamin $\mathrm{D}$ (including oral and injection products) during the last 6 months.

For the severity of pain, Quadruple VAS (Visual Analogue Scale) was used.

The analysis of the collected data was with IBM SPSS statistics package ver. 20.0 (IBM, Armonk, NY, USA). It was used for the descriptive statistics including the means, ratios and their confidence intervals, and also the diagrams and tables. Statistical tests included the independent $t$-test, one-way analysis of variance, chi-square, univariate and multivariate binary logistic regression analysis. The significance level was set at 0.05 for all the statistical tests.

The study was evaluated by Ethics Committee for Medical Research at Isfahan University of Medical Sciences (approval/ registration number 493054).

\section{Results}

A total of 110 patients entered the study. The lowest and the highest levels of $25(\mathrm{OH}) \mathrm{D}$ measured were $3 \mathrm{ng} / \mathrm{mL}$ and $70 \mathrm{ng} / \mathrm{mL}$, respectively. The mean serum level of $25(\mathrm{OH})$ D was $27.45 \pm 18.75 \mathrm{ng} / \mathrm{mL}$. For the studied population, 49 (44.5\%), $19(17.3 \%)$, and $42(38.2 \%)$ of the subjects were in the deficient, insufficient, and normal groups, respectively.

\section{Supplement consumption and vitamin D serum levels}

In total, 42 patients (38.5\%) had a history of consumption of vitamin D supplements during the last 6 months. The groups with and without the history of the consumption of vitamin D supplement showed the mean serum level of $25(\mathrm{OH}) \mathrm{D}$ as $37.33 \pm 20.31$ and $21.06 \pm 14.78 \mathrm{ng} / \mathrm{mL}$, respectively $(p<0.001)$. Table 1 shows the supplement consumption status in different groups according to age, sex and smoking.

\section{Type of pathology and vitamin D serum levels}

According to the type of pathology, five groups were defined as follows: (1) lumbar disc herniation, (2) lumbar spine stenosis, (3) lumbar spine instability, (4) cervical disc herniation, and (5) cervical spine stenosis.

However in some cases there was a combination of pathologies; in such cases, the predominant pathology was used for the classification. Frequency, vitamin D serum level and also supplement consumption status of these groups are shown in Table 2. There were 19 patients (17.3\%) with cervical spine pathology of the studied population and 91 patients $(82.7 \%)$ with the lumbosacral spine pathology. The mean serum level of $25(\mathrm{OH}) \mathrm{D}$ was $14.87 \pm 10.86$ and $30.07 \pm 19.02 \mathrm{ng} / \mathrm{mL}$ in these two groups, respectively $(p<0.001)$. 
Table 2. Distribution of all patients, supplement consumption and vitamin D serum level in different groups of pathologies

\begin{tabular}{|c|c|c|c|}
\hline \multirow{2}{*}{ Type of pathology } & \multicolumn{2}{|c|}{ All Subjects } & \multirow{2}{*}{$\begin{array}{l}\text { Supplement } \\
\text { consumption }\end{array}$} \\
\hline & Frequency $(\%)$ & $25(\mathrm{OH}) \mathrm{D}$ & \\
\hline Lumbar disc herniation & $34(32.1)$ & $24.03 \pm 15.75$ & $7(20.6)$ \\
\hline Lumbar spine stenosis & $29(27.4)$ & $34.99 \pm 21.73$ & $14(48.3)$ \\
\hline Lumbar spine instability & $24(22.6)$ & $34.08 \pm 18.84$ & $13(56.5)$ \\
\hline Cervical disc herniation & $12(11.3)$ & $11.80 \pm 7.50$ & $3(25)$ \\
\hline Cervical spine stenosis & $7(6.6)$ & $20.14 \pm 14.13$ & $3(42.9)$ \\
\hline
\end{tabular}

Values are presented as number (\%) or mean \pm standard deviation.

\section{Age and vitamin D serum levels}

The youngest and the oldest subjects were 22 and 78 years old. The mean age of the population was $47.06 \pm 11.94$ years.

The mean serum level of $25(\mathrm{OH}) \mathrm{D}$ was $18.94 \pm 14.77$ $\mathrm{ng} / \mathrm{mL}$ in the young group. It was $28.36 \pm 18.99$ and $39.36 \pm 17.88 \mathrm{ng} / \mathrm{mL}$ in the middle-aged and old groups, respectively $(p=0.003)$.

The relationship between the different age groups was studied using the additional test (Post Hoc) of LSD, and it was found out that in all cases the level of $25(\mathrm{OH}) \mathrm{D}$ was significantly higher in the older age group and the highest difference was observed between the young and old groups ( $p=0.001$ ). There was no significant difference between different age groups in terms of the history of vitamin D supplement use $(p=0.58)$.

\section{Sex and vitamin D serum levels}

The studied population consisted of 54 male (49.1\%) and 56 female (50.9\%) patients. The mean serum level of $25(\mathrm{OH}) \mathrm{D}$ was $31.08 \pm 20.74 \mathrm{ng} / \mathrm{mL}$ in women and $23.68 \pm 15.76 \mathrm{ng} / \mathrm{mL}$ in men $(p=0.037)$. Also, vitamin $\mathrm{D}$ supplement consumption was significantly higher in women $(p<0.001)$.

\section{Smoking and vitamin D serum levels}

For the population, 15 (13.9\%) and 93 (86.1\%) subjects were smokers and non-smokers, respectively. The mean serum level of $25(\mathrm{OH}) \mathrm{D}$ was $19.31 \pm 15.77$ and $28.69 \pm 19.12 \mathrm{ng} / \mathrm{mL}$ in smokers and non-smokers, respectively $(p=0.074)$. The consumption of vitamin D supplements was significantly higher in non-smokers $(p=0.032)$.

\section{6. $B M I$ and vitamin $D$ serum levels}

In the studied population, 3 (2.9\%), 30 (28.6\%), 44 (41.9\%), and 28 subjects (26.7\%) were in the underweight, normal, overweight, and obese categories, respectively. The mean serum level of $25(\mathrm{OH}) \mathrm{D}$ was $12.33 \pm 9.2$, $24.05 \pm 17.23,28.37 \pm 17.55$, and $25.95 \pm 19.07 \mathrm{ng} / \mathrm{mL}$ in underweight, normal, over weight and obese groups, respectively $(p=0.408)$.

\section{VAS score and vitamin D serum levels}

The mean VAS score in the three vitamin D groups was as follows: $73.12 \pm 12.50,69.47 \pm 11.07$, and $73.57 \pm 12.94$ in deficient, insufficient, and normal groups, respectively $(p=0.467)$.

\section{Season of the year for the testing and vitamin $D$ serum levels}

Sampling was performed from late in fall of 2013 to late in summer of 2014. From a total of 110 tests, 52 tests (47.3\%) were performed in the spring, 12 tests (10.9\%) in the summer, 4 tests (3.6\%) in the autumn and 42 tests (38.2\%) in the winter.

The mean serum level of $25(\mathrm{OH}) \mathrm{D}$ was $27.51 \pm 19.74$, $23.38 \pm 14.85,16.75 \pm 12.63$, and $29.55 \pm 18.94 \mathrm{ng} / \mathrm{mL}$ in the spring, summer, fall, and winter, respectively $(p=0.5)$.

The univariate binary logistic regression analysis was used to assess each of the potential risk factors related to the vitamin $\mathrm{D}$ deficiency and to determine the odds ratio (OR). The relevant results are shown in Table 3.

After the multivariate binary logistic regression analysis, only the age (adjusted OR, 0.17; 95\% confidence interval [CI], 0.063-0.457; $p<0.001)$ and vitamin D supplement 
Table 3. Result from Univariate binary logistic regression analysis for potential risk factors of vitamin $D$ deficiency

\begin{tabular}{|c|c|c|c|c|c|}
\hline variable & $\begin{array}{l}25(\mathrm{OH}) \mathrm{D}<30 \\
\text { frequency }(\%)\end{array}$ & $\begin{array}{l}30 \leq 25(\mathrm{OH}) \mathrm{D} \\
\text { frequency }(\%)\end{array}$ & Odds ratio & $\begin{array}{c}95 \% \text { Confidence } \\
\text { interval }\end{array}$ & $p$-value \\
\hline \multicolumn{6}{|c|}{ Vitamin D supplement } \\
\hline Yes & $20(47.6)$ & $22(52.4)$ & Reference & - & - \\
\hline No & 48 (71.6) & $19(28.4)$ & 2.779 & $1.242-6.219$ & 0.013 \\
\hline \multicolumn{6}{|l|}{ Age group } \\
\hline Young & $25(92.6)$ & $2(7.4)$ & 45.833 & $6.689-314.07$ & $<0.001$ \\
\hline Middle age & $40(58.0)$ & $29(42.0)$ & 5.057 & $1.294-19.767$ & 0.02 \\
\hline Elderly & $3(21.4)$ & $11(78.6)$ & Reference & - & - \\
\hline \multicolumn{6}{|l|}{ Sex } \\
\hline Male & 39 (72.2) & $15(27.8)$ & 2.421 & $1.095-5.351$ & 0.029 \\
\hline Female & 29 (51.8) & 27 (48.2) & Reference & - & - \\
\hline \multicolumn{6}{|l|}{ Smoking } \\
\hline Yes & $12(80.0)$ & $3(20)$ & 2.764 & $0.73-10.46$ & 0.134 \\
\hline No & 55 (59.1) & 38 (40.9) & Reference & - & - \\
\hline \multicolumn{6}{|l|}{ Body mass index } \\
\hline Underweight & $3(100.0)$ & 0 & 0 & 0 & 1 \\
\hline Normal & $22(73.3)$ & 8 (26.7) & Reference & - & - \\
\hline Overweight & $25(56.8)$ & 19 (43.2) & 0.478 & $0.175-1.308$ & 0.151 \\
\hline Obese & $18(64.3)$ & $10(35.7)$ & 0.655 & $0.214-2.004$ & 0.458 \\
\hline \multicolumn{6}{|l|}{ Season } \\
\hline Spring & 32 (61.5) & $20(38.5)$ & 0.8 & $0.213-3.006$ & 0.741 \\
\hline Summer & $8(66.7)$ & 4 (33.3) & Reference & - & - \\
\hline Autumn & $3(75.0)$ & $1(25.0)$ & 1.5 & $0.116-19.437$ & 0.756 \\
\hline Winter & $25(59.5)$ & $17(40.5)$ & 0.735 & $0.191-2.834$ & 0.655 \\
\hline
\end{tabular}

consumption (adjusted OR, 2.874; 95\% CI, 1.104-7.482; $p=0.031$ ) remained as predictors for deficiency. Factors entered in this analysis were age, sex, smoking status, supplement consumption, BMI and season of the year for the test.

\section{Discussion}

Although, the degeneration of the vertebral discs is considered a part of a natural trend in aging, it can become accelerated, with the affected individual becoming symptomatic at a younger age. This degeneration can most likely be accounted for by mostly a genetic predisposition and partly by environmental factors. The environmental factors such as heavy physical activity can trigger a cascade of molecular events in disc degeneration, exacerbating the disorder in a vicious cycle. One of the factors playing a role in these molecular processes is the vitamin D system. Of note, VDRs (vitamin D receptors) are expressed in osteoblasts, chondrocytes, and annulus fibrosus and nucleus pulposus cells of the discs $[3,4]$. In addition, vitamin D has been demonstrated to affect the proliferation and functional regulation of these cells and their production of certain proteins and cytokines in vitro.

However, degenerative changes in bone and cartilage, either because of the natural aging or disease, can lead to fractures, spine instability and deformity, which can in turn result in chronic pain and neurological deficits. Also, a poor quality of bone affects the outcome of spine surgeries, especially instrumented ones, resulting in undesirable consequences.

In a study of 360 patients with chronic LBP, the prevalence of severe vitamin D deficiency $(<9 \mathrm{ng} / \mathrm{mL})$ was reported as $83 \%$ [15]. Stoker et al. [7] studied 313 patients 
undergoing surgical spinal fusion and reported that the prevalence of vitamin D deficiency $(<20 \mathrm{ng} / \mathrm{mL})$ was $27 \%$ and the prevalence of insufficiency $(<30 \mathrm{ng} / \mathrm{mL})$ was $57 \%$. Also, in a study of the prevalence of vitamin D deficiency in patients with lumbar spinal stenosis (LSS) and its relation with pain, the prevalence of hypovitaminosis $\mathrm{D}$ was reported as $74.3 \%$ [10].

In the present study, we examined the vitamin $\mathrm{D}$ serum level status of the patients undergoing surgery for degenerative diseases of the spine and the relationship between the serum levels of vitamin D and the factors that can act as risk factors for vitamin $\mathrm{D}$ deficiency for these patients. A total of 110 patients were enrolled. Of these, 49 patients (44.5\%) suffered from the vitamin D deficiency; also 19 (17.3\%) had insufficient levels of vitamin D; the remaining 42 patients (38.2\%) had normal serum levels. As such, $61.8 \%$ suffered from hypovitaminosis $\mathrm{D}(25(\mathrm{OH}) \mathrm{D}<30$ $\mathrm{ng} / \mathrm{mL}$ ), which is a considerable percentage of these patients. For the group with no history of the consumption of vitamin D supplement, the rate was $71.6 \%$. Although the mean serum level of $25(\mathrm{OH}) \mathrm{D}$ was significantly higher in the group with a consumption history of vitamin D supplements $(p=0.013$ ), hypovitaminosis D prevalence was still $47.6 \%$, indicating inadequate or incorrect levels of vitamin D supplementation.

For patients undergoing cervical spine surgery, they made up only a small percentage of the patients in our study (19 subjects) and although their numbers may not be representative, 17 of 19 the patients (89.5\%) suffered from hypovitaminosis D and only 2 patients (10.5\%) showed normal vitamin $\mathrm{D}$ levels. On the contrary, patients undergoing lumbosacral spine surgery (91 subjects), only $56.1 \%$ suffered from hypovitaminosis D.

In terms of age of patients, older age has been traditionally reported as a risk factor for vitamin D deficiency and various reports have stated the high prevalence of vitamin D deficiency in older people [16]. Also, the mechanisms such as the reduced capacity of intestinal absorption and the reduced skin synthesis of vitamin D are discussed in the context of aging [17]. However, clinical studies, particularly those for the spine, have shown that the age cannot be a good predictor of vitamin D deficiency. Moreover, studies conducted on patients with orthopedic surgery and spinal fusion have found a high prevalence of vitamin D deficiency in young adults $[7,18]$. Our study also revealed a significant direct correlation $(p<0.001)$ between age and serum levels of $25(\mathrm{OH}) \mathrm{D}$, which was independent of the effect resulting from the consumption of vitamin $\mathrm{D}$ supplement. The highest rate of vitamin D deficiency was seen for the 20-39-year-old age group. Considering this, care should be taken that although the aging population suffers from osteoporosis, osteomalacia, fractures and degenerative processes, young people should not be neglected. It may be that many of these pathological processes start early at youth and controlling vitamin D levels at a young age might prevent degenerative spine diseases later in life.

Females are regarded to be at risk for vitamin $\mathrm{D}$ deficiency and many studies have confirmed this [19]. However, in a number of studies, there were no differences between female and male subjects for vitamin D deficiency [20] and even in some cases, it was shown a lower risk for hypovitaminosis D existed in females [18,21]. Also, in our study, the serum levels of 25(OH)D were significantly higher in women among the studied population $(p=0.029)$. Moreover, vitamin D supplement consumption was considerably and significantly higher in women $(p<0.001)$, and the higher vitamin D levels in this group may be due to the increased dietary supplementation and treatment in this group.

Research and data about vitamin D status in the general adult population in our country is very limited. In these studies [22,23] prevalence of vitamin D deficiency has been reported to be from $30 \%$ to $80 \%$, according to population and regional differences. In the only study of adult population in our region (Isfahan, Iran) prevalence of hypovitaminosis D was reported to be about 70\% [23] and the deficiency was more prevalent in women and youth. The main problem of this study was that about $80 \%$ of the studied population were female.

Some assumptions have been suggested for smoking and its effects on the musculoskeletal system with indications of reduced intestinal absorption of calcium and increased rate of bone loss [24]. In this study, there was no significant difference in the serum levels of vitamin $D$ between the smokers and non-smokers $(p=0.134)$. The only noteworthy point was that the vitamin $\mathrm{D}$ supplement consumption was significantly higher in the non-smoker group ( $p=0.032$ ).

What should be stated about BMI as a risk factor for vitamin $\mathrm{D}$ deficiency is that in obese patients, an increase in adipose tissue leads to dispersion and distribution of this fat-soluble vitamin and thus a reduction in its bioavailability [7]. In this case, many studies suggest an 
inverse relationship between BMI and the serum levels of vitamin D $[18,25]$. However, several clinical studies have also indicated a high prevalence of vitamin D deficiency in non-obese patients [26]. In our study, there was no significant correlation between the serum levels of $25(\mathrm{OH})$ $\mathrm{D}$ and BMI ( $p=0.458)$; this was similar to the results of the study by Kim et al. [10] where they reported on 350 patients with LSS. This was unlike the finding by Stoker et al. [7] in a study of 313 patients undergoing spinal fusion surgery where there was a high prevalence of vitamin $\mathrm{D}$ deficiency in obese individuals.

In the case of presence of pain, there have been several reports on the relationship between musculoskeletal pain and vitamin D deficiency $[15,20,27]$, and it was demonstrated that treatment by vitamin $\mathrm{D}$ supplements could improve the symptoms $[15,27]$. In particular, in the case of the spine, both Stoker et al. [7] and Kim et al. [10] suggested an inverse correlation between the pain and the serum levels of vitamin D. Similar results have been reported for patients with chronic LBP and unsuccessful fusion surgery $[15,28]$. In spite of the abovementioned studies, we did not find any significant correlation between the severity of pain and the serum levels of vitamin $\mathrm{D}(p=0.467)$.

It is believed that individuals who live in more northern latitude are at a higher risk of vitamin D deficiency in winter. This also includes individuals who in any way may have a limited exposure to sunlight [29]. However, several clinical studies [30] showed a high prevalence of vitamin $\mathrm{D}$ deficiency in lower latitudes and in summer, among them in our country (Iran) where there is a good deal of sunlight and there is still a high prevalence of vitamin $\mathrm{D}$ deficiency. In the present study, similar to what were stated in the studies by Stoker et al. [7] and Kim et al. [10], there was not a significant difference between the serum levels of vitamin D and the different seasons $(p=0.655)$. For our study, however, the distribution of samples was not uniform in different seasons and most of samples (85.5\%) were collected in spring and winter.

\section{Conclusions}

In summary, according to the results from the present study and similar to other studies in this area, it can be stated that the vitamin $\mathrm{D}$ deficiency shows a high prevalence in patients with degenerative diseases of the spine, even in patients treated by vitamin $\mathrm{D}$ supplements.
Although vitamin D has attracted the attention of researchers in recent decades and its role has been studied and confirmed in various diseases, with knowledge and awareness having increased among the public and medical professionals, it has not yet been enough. Although the elderly and women are traditionally at a higher risk of vitamin D deficiency with consequences such as osteomalacia, osteoporosis, etc., there is also no safety margin for vitamin D deficiency among youths and men and they should not be ignored. On the other hand, given the diversity and differences in research results for vitamin $\mathrm{D}$ deficiency risk factors, they are not enough for predicting or proposing vitamin $\mathrm{D}$ deficiency and it is recommended that vitamin D deficiency prevention strategies comprise a broader spectrum of the population in order to prevent or delay the onset of degenerative diseases and their consequences. In addition, considering that vitamin D deficiency existed even for patients treated with supplements, attention should be paid to the correct and complete dosing after diagnosing the vitamin D deficiency.

\section{Conflict of Interest}

No potential conflict of interest relevant to this article was reported.

\section{Acknowledgments}

The authors appreciate Dr. N. Almasi-the head of Shariati hospital laboratory-and also staff of laboratory and neurosurgery ward of the hospital for cooperation during project implementation.

\section{References}

1. Atkin I, Pita JC, Ornoy A, Agundez A, Castiglione G, Howell DS. Effects of vitamin D metabolites on healing of low phosphate, vitamin D-deficient induced rickets in rats. Bone 1985;6:113-23.

2. Beck L, Silve C. Molecular aspects of renal tubular handling and regulation of inorganic sulfate. Kidney Int 2001;59:835-45.

3. Gruber HE, Hoelscher G, Ingram JA, Chow Y, Loeffler B, Hanley EN Jr. 1,25(OH)2-vitamin D3 inhibits proliferation and decreases production of monocyte chemoattractant protein-1, thrombopoietin, VEGF, and angiogenin by human annulus cells in vitro. 
Spine (Phila Pa 1976) 2008;33:755-65.

4. Colombini A, Lanteri P, Lombardi G, et al. Metabolic effects of vitamin $\mathrm{D}$ active metabolites in monolayer and micromass cultures of nucleus pulposus and annulus fibrosus cells isolated from human intervertebral disc. Int J Biochem Cell Biol 2012;44:1019-30.

5. Rubin DI. Epidemiology and risk factors for spine pain. Neurol Clin 2007;25:353-71.

6. Borenstein DG. Epidemiology, etiology, diagnostic evaluation, and treatment of low back pain. Curr Opin Rheumatol 2001;13:128-34.

7. Stoker GE, Buchowski JM, Bridwell KH, Lenke LG, Riew KD, Zebala LP. Preoperative vitamin D status of adults undergoing surgical spinal fusion. Spine (Phila Pa 1976) 2013;38:507-15.

8. Kim TH, Yoon JY, Lee BH, et al. Changes in vitamin $\mathrm{D}$ status after surgery in female patients with lumbar spinal stenosis and its clinical significance. Spine (Phila Pa 1976) 2012;37:E1326-30.

9. Lee BH, Moon SH, Kim HJ, Lee HM, Kim TH. Osteoporotic profiles in elderly patients with symptomatic lumbar spinal canal stenosis. Indian J Orthop 2012;46:279-84.

10. Kim TH, Lee BH, Lee HM, et al. Prevalence of vitamin $\mathrm{D}$ deficiency in patients with lumbar spinal stenosis and its relationship with pain. Pain Physician 2013;16:165-76.

11. Holick MF, Binkley NC, Bischoff-Ferrari HA, et al. Evaluation, treatment, and prevention of vitamin D deficiency: an Endocrine Society clinical practice guideline. J Clin Endocrinol Metab 2011;96:1911-30.

12. Bischoff-Ferrari HA, Giovannucci E, Willett WC, Dietrich T, Dawson-Hughes B. Estimation of optimal serum concentrations of 25-hydroxyvitamin D for multiple health outcomes. Am J Clin Nutr 2006;84: 18-28.

13. Vieth R. Why the minimum desirable serum 25hydroxyvitamin D level should be $75 \mathrm{nmol} / \mathrm{L}$ (30 ng/ ml). Best Pract Res Clin Endocrinol Metab 2011;25: 681-91.

14. Centers for Disease Control and Prevention. About BMI for adults [Internet]. Atlanta: Centers for Disease Control and Prevention; 2014 [cited 2016 Aug 13]. Available from: http://www.cdc.gov/healthyweight/assessing/bmi/adult_bmi/index.html.

15. Al Faraj S, Al Mutairi K. Vitamin D deficiency and chronic low back pain in Saudi Arabia. Spine (Phila
Pa 1976) 2003;28:177-9.

16. Jacques PF, Felson DT, Tucker KL, et al. Plasma 25-hydroxyvitamin $\mathrm{D}$ and its determinants in an elderly population sample. Am J Clin Nutr 1997;66: 929-36

17. Holick MF. Vitamin D deficiency. N Engl J Med 2007; 357:266-81.

18. Bogunovic L, Kim AD, Beamer BS, Nguyen J, Lane JM. Hypovitaminosis D in patients scheduled to undergo orthopaedic surgery: a single-center analysis. J Bone Joint Surg Am 2010;92:2300-4.

19. Rodriguez WJ, Gromelski J. Vitamin d status and spine surgery outcomes. ISRN Orthop 2013;2013: 471695.

20. Plotnikoff GA, Quigley JM. Prevalence of severe hypovitaminosis $\mathrm{D}$ in patients with persistent, nonspecific musculoskeletal pain. Mayo Clin Proc 2003; 78:1463-70.

21. Guardia G, Parikh N, Eskridge T, Phillips E, Divine G, Rao DS. Prevalence of vitamin D depletion among subjects seeking advice on osteoporosis: a five-year cross-sectional study with public health implications. Osteoporos Int 2008;19:13-9.

22. Ebrahimi M, Khashayar P, Keshtkar A, et al. Prevalence of vitamin D deficiency among Iranian adolescents. J Pediatr Endocrinol Metab 2014;27:595-602.

23. Hovsepian S, Amini M, Aminorroaya A, Amini P, Iraj B. Prevalence of vitamin D deficiency among adult population of Isfahan City, Iran. J Health Popul Nutr 2011;29:149-55.

24. Krall EA, Dawson-Hughes B. Smoking increases bone loss and decreases intestinal calcium absorption. J Bone Miner Res 1999;14:215-20.

25. Arunabh S, Pollack S, Yeh J, Aloia JF. Body fat content and 25-hydroxyvitamin D levels in healthy women. J Clin Endocrinol Metab 2003;88:157-61.

26. Growdon AS, Camargo CA Jr, Clark S, Hannon M, Mansbach JM. Serum 25-hydroxyvitamin D levels among Boston trainee doctors in winter. Nutrients 2012;4:197-207.

27. Ahmed W, Khan N, Glueck CJ, et al. Low serum 25 $(\mathrm{OH})$ vitamin D levels $(<32 \mathrm{ng} / \mathrm{mL})$ are associated with reversible myositis-myalgia in statin-treated patients. Transl Res 2009;153:11-6.

28. Waikakul S. Serum 25-hydroxy-calciferol level and failed back surgery syndrome. J Orthop Surg (Hong Kong) 2012;20:18-22. 
29. Webb AR, Kline L, Holick MF. Influence of season and latitude on the cutaneous synthesis of vitamin D3: exposure to winter sunlight in Boston and Edmonton will not promote vitamin D3 synthesis in human skin. J Clin Endocrinol Metab 1988;67:373-8.

30. Binkley N, Novotny R, Krueger D, et al. Low vitamin D status despite abundant sun exposure. J Clin Endocrinol Metab 2007;92:2130-5. 